\title{
Overexpression of the Rat Inducible 70-kD Heat Stress Protein in a Transgenic Mouse Increases the Resistance of the Heart to Ischemic Injury
}

\author{
Michael S. Marber, ${ }^{*}$ Ruben Mestril, Shun-Hua Chi, M. Richard Sayen, Derek M. Yellon, ${ }^{*}$ and Wolfgang H. Dillmann \\ The Department of Medicine, Division of Endocrinology and Metabolism, University of California at San Diego, San Diego, \\ California 92103; and *The Hatter Institute for Cardiovascular Studies, Department of Academic and Clinical Cardiology, \\ University College Hospital, London WC1E 6DB United Kingdom
}

\begin{abstract}
Myocardial protection and changes in gene expression follow whole body heat stress. Circumstantial evidence suggests that an inducible 70-kD heat shock protein (hsp70i), increased markedly by whole body heat stress, contributes to the protection. Transgenic mouse lines were constructed with a cytomegalovirus enhancer and $\beta$-actin promoter driving rat hsp70i expression in heterozygote animals. Unstressed, transgene positive mice expressed higher levels of myocardial hsp70i than transgene negative mice after whole body heat stress. This high level of expression occurred without apparent detrimental effect. The hearts harvested from transgene positive mice and transgene negative littermates were Langendorff perfused and subjected to 20 min of warm $\left(37^{\circ} \mathrm{C}\right)$ zero-flow ischemia and up to $120 \mathrm{~min}$ of reflow while contractile recovery and creatine kinase efflux were measured. Myocardial infarction was demarcated by triphenyltetrazolium. In transgene positive compared with transgene negative hearts, the zone of infarction was reduced by $\mathbf{4 0 \%}$, contractile function at $30 \mathrm{~min}$ of reflow was doubled, and efflux of creatine kinase was reduced by $\sim 50 \%$. Our findings suggest for the first time that increased myocardial hsp70i expression results in protection of the heart against ischemic injury and that the antiischemic properties of hsp70i have possible therapeutic relevance. (J. Clin. Invest. 1995. 95:1446-1456.) Key words: myocardial infarction • myocardial protection $\cdot$ heat shock proteins
\end{abstract}

\section{Introduction}

A number of independent investigators have shown that $24 \mathrm{~h}$ after whole body temperature elevation to $42^{\circ} \mathrm{C}$ for $15 \mathrm{~min}$ the heart shows enhanced protection against ischemic injury (17 ). This whole body heat stress procedure has been shown to reduce infarct size in vivo (1-3) and in vitro (4) and to enhance

M. S. Marber and R. Mestril contributed equally to this manuscript. This work was presented in part at the 67th Scientific Session of the American Heart Association in Dallas on 14-17 November 1994 (1994. Circulation. 90 [Suppl. I]:I-536).

Address correspondence to Dr. Wolfgang Dillmann, University of California at San Diego, 200 West Arbor Drive (8412), San Diego, CA 92013. Phone: 619-543-5912; FAX: 619-543-3306.

Received for publication 29 August 1994 and in revised form 4 November 1994.

J. Clin. Invest.

(c) The American Society for Clinical Investigation, Inc.

$0021-9738 / 95 / 04 / 1446 / 11 \quad \$ 2.00$

Volume 95, April 1995, 1446-1456 postischemic contractile function in vitro (5-7). $24 \mathrm{~h}$ after heat stress a change must therefore occur within the heart that gives rise to this protection. The exact nature of this change is at present uncertain $(8,9)$. However, a number of lines of evidence suggest that alterations in myocardial stress proteins and/ or antioxidant enzymes are of particular importance $(8,9)$.

Among the myocardial stress proteins increased after heat stress, an inducible member of the hsp70 family (hsp70i) ${ }^{1}$ shows marked changes (1-7), and its possible involvement in myocardial protection has been shown by a number of studies. In a papillary muscle model, hsp70i concentration correlated with resistance to substrate deprivation (10), similarly in vivo infarct size was negatively correlated with myocardial hsp70i content (11). Unfortunately both these studies $(10,11)$ provide only circumstantial evidence to link hsp70i to protection. For example, hsp70i content is likely to be related to the severity of the heat stress procedure and thus co-correlate with other thermally induced changes within the myocardium (10). Other evidence linking hsp70i to myocardial protection has been derived from in vitro studies that demonstrate that an embryonal heart-derived cell line becomes resistant to simulated ischemia after stable transfection with an hsp70i-encoding plasmid (12, 13). However, such studies are not directly relevant to true ischemia in the whole heart.

The antioxidant enzyme catalase is also increased within the myocardium $24 \mathrm{~h}$ after whole body heat stress (5). Catalase is relevant to protection since it may be capable of reducing the free-radical injury associated with myocardial ischemia/ reperfusion (14). In addition, inhibiting catalase can at least partially abolish post-heat stress protection when contractility is used as the endpoint of injury (15), although results are more difficult to interpret when other endpoints are considered $(7,16)$.

To overcome these difficulties, attempts have been made to induce myocardial hsp70i more specifically by nonthermal stress. For example, short sublethal episodes of cardiac ischemia both increase myocardial hsp70i $(2,17)$ and result in cardiac protection $(2,18)$, but increases also occur in a $60-\mathrm{kD}$ stress protein (2) and in another myocardial antioxidant enzyme, superoxide dismutase (19).

At present it is therefore uncertain which of the changes observed within the myocardium after thermal and other stresses is responsible for protection. This knowledge is a prerequisite to targeted interventions designed to trigger the benefits but avoid the abuse associated with whole body heat stress.

1. Abbreviations used in this paper: $\mathrm{CK}$, creatine kinase; CMV, cytomegalovirus; hsp70c, constitutive member of the $70-\mathrm{kD}$ heat stress protein family; hsp70i, inducible member of the $70-\mathrm{kD}$ heat stress protein family; mhsp70i, mouse inducible heat stress protein 70; rhsp70i, rat inducible heat stress protein 70 . 


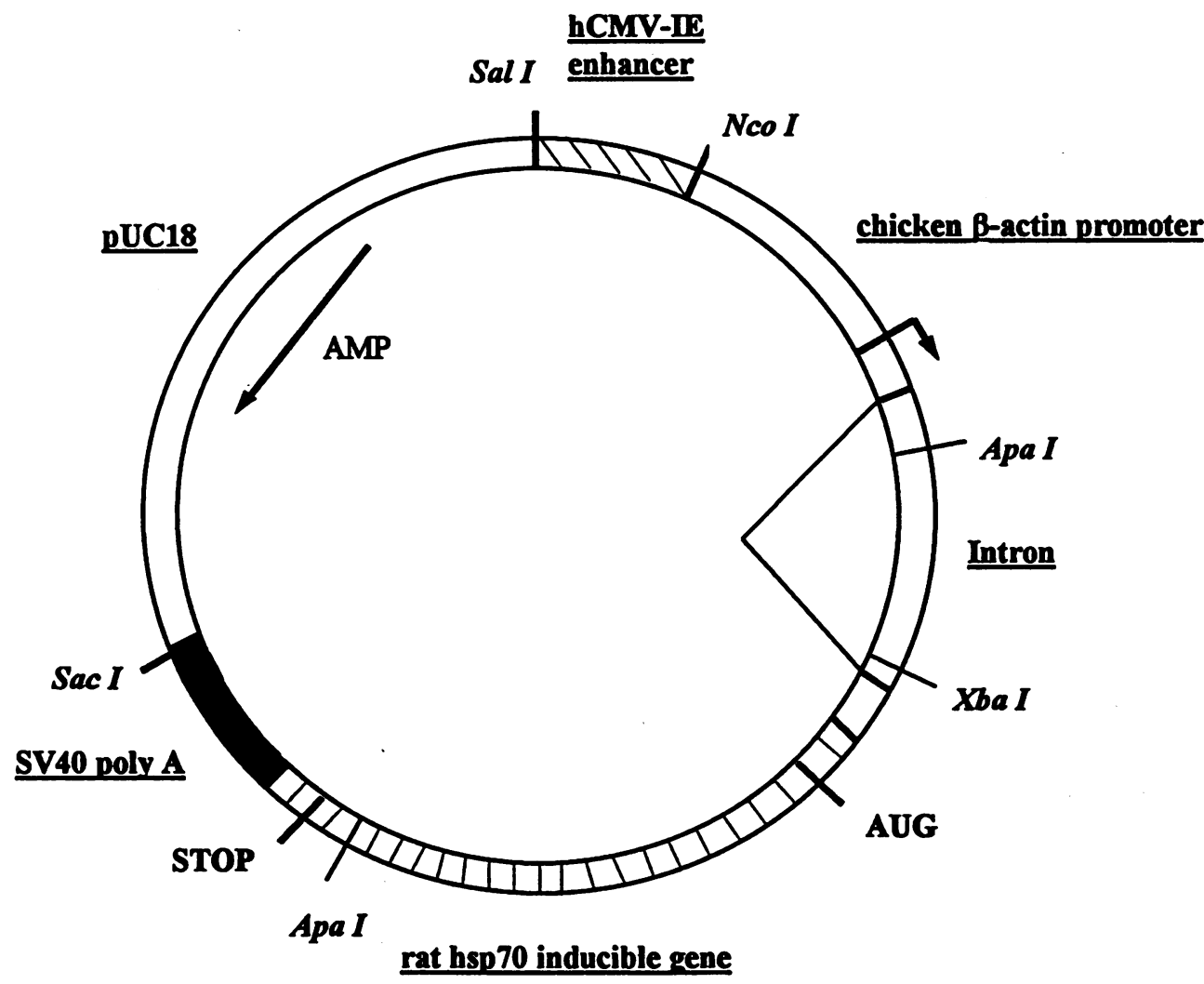

Figure 1. Map of the hCMV $\beta$ actin/rhsp70i transgene. The coding region of the rat inducible 70$\mathrm{kD}$ heat shock protein gene (rhsp70i) is under the control of the human CMV immediate-early (hCMV-IE) enhancer and chicken $\beta$-actin promoter with first intron. The rhsp70i coding region is followed by the SV40 polyadenylation signal. The SalI to SacI fragment was used to generate transgenic mice. The 3.5-kb fragment generated by ApaI digestion of genomic DNA from the tails of transgenic mice was detected on Southern blots by a probe prepared from the ApaI to XbaI fragment.

Our aim was to determine which component of the myocardial response to stress is likely to be responsible for ischemic protection. In light of the evidence discussed above, together with a wealth of information regarding the protective role of the hsp70 family in a variety of cell types against various injuries (for review see reference 20), we felt that hsp70i was the candidate most likely responsible for protection. We examined this hypothesis by producing a transgenic mouse line overexpressing hsp70i within the heart and determining the resistance of these hearts to ischemia.

\section{Methods}

The development of the transgenic mouse line. Transgenic mice were generated using a chimeric transgene consisting of a rat inducible hsp70 (rhsp70i) gene (21) inserted into the vector pCAGGS (22). The rhsp70i amino acid sequence is $95 \%$ identical to that of the human hsp70i and $97 \%$ identical to that of the mouse hsp70i (21). The pCAGGS construct places the rhsp70i gene under the control of the human cytomegalovirus immediate early enhancer (hCMV-IE) and chicken $\beta$-actin promoter with first intron (22) (Fig. 1). The chimeric transgene was cut out of the plasmid by SalI and SacI digestion, purified, and used to generate transgenic mice (23).

In brief, the male pronuclei of fertilized eggs from hyperovulated B6 $\times$ SJL mice were injected with 1-2 pl of DNA solution at a concentration of $2 \mu \mathrm{g} / \mathrm{ml}$, equivalent to $200-400$ copies of the transgene. Injected eggs were transferred into the oviduct of pseudopregnant CD1 mice. 20 injected eggs were implanted per mouse, and litters were delivered after 19-20 d of gestation.

When mice were 3 wk old, genomic DNA was isolated from 1-cm tail clips and subjected to Southem blotting as follows. The ApaI digests of genomic DNA were separated by electrophoresis, blotted onto a nylon membrane, and hybridized with a $\left[{ }^{32} \mathrm{P}\right]$-labeled probe. The probe used was the ApaI to XbaI fragment from the hCMV- $\beta$-actin/rhsp70i transgene construct (Fig. 1) and contained the chicken $\beta$-actin promoter and intron. If the chimeric transgene was present in the genome, ApaI digestion would result in a $3.5-\mathrm{kb}$ fragment which would specifically hybridize with the probe.

Founder mice, that had integrated the transgene, were bred with mice of the same strain $(B 6 \times S J L)$. The resultant litters were analyzed by Southern blotting of tail clips as described above. Transgene positive mice (heterozygotes) and transgene negative littermates were then used for the experiments described below.

The level of expression of the transgene at the transcript and protein level was examined by Northern and Western blotting using protocols that we have described previously $(10,12)$. Transgene negative littermates served as negative controls, and positive controls were obtained by heat stressing mice to $42^{\circ} \mathrm{C}$ for 15 min using a technique described elsewhere (24). The possible influence that expression of the chimeric rhsp70i transgene could have on the expression of other heat shock proteins was examined by stripping and rehybridizing Northern membranes with probes for hsp60, hsp90, and hsp27.

The Langendorff perfused mouse heart. Transgene positive and transgene negative mice were anesthetized by intraperitoneal injection of ketamine (Aveco Co, Fort Dodge, IA) $150 \mathrm{mg} / \mathrm{kg}$ and xylazine (Lloyd Laboratories, Shenandoah, IA) $24 \mathrm{mg} / \mathrm{kg}$ coadministered with $10.8 \mathrm{ml} / \mathrm{kg}$ of normal saline and $100 \mathrm{IU}$ of heparin. Once the mouse was deeply anesthetized, the heart was removed by sternectomy and trimmed under a dissecting microscope while in iced Tyrode's solution. The aorta was then cannulated, with a $20 \mathrm{G}$ phalanged stainless steel cannula, under the Tyrode's solution to prevent air embolization of the coronary circulation. Once the aorta had been tightly secured using 4/ 0 silk suture, the cannula was transferred to the perfusion rig. During transfer the cannula was continuously perfused through a side arm with Tyrode's solution under low pressure to ensure that no air entered the cannula or connectors. Side arm perfusion was stopped once the cannula was rigidly attached to the perfusion rig and retrograde perfusion at 80 $\mathrm{mmHg}$ had commenced. 
The heart was perfused with modified Tyrode's solution of the following composition: $\mathrm{NaCl} 118.0 \mathrm{mM}, \mathrm{NaHCO}_{3} 24.0 \mathrm{mM}, \mathrm{KCl} 4.0 \mathrm{mM}$, $\mathrm{NaH}_{2} \mathrm{PO}_{4} 1.0 \mathrm{mM}, \mathrm{CaCl}_{2} 2.5 \mathrm{mM}, \mathrm{MgCl}_{2} 1.2 \mathrm{mM}$, di-sodium EDTA $0.5 \mathrm{mM}$, sodium pyruvate $2.0 \mathrm{mM}$, glucose $10.0 \mathrm{mM}$, prefiltered to 0.22 $\mu \mathrm{m}$ and equilibrated with $95 \% \mathrm{O}_{2} / 5 \% \mathrm{CO}_{2}$.

Under direct vision a small incision was made in the pulmonary artery immediately above the right ventricular outflow, to allow free drainage of coronary effluent. Through this incision a micro-thermocouple (type K) connected to a digital thermometer (Physitemp Bat-12; Sensortek, Clifton, NJ) was introduced retrogradely into the right ventricle. 4/0 silk suture on a round bodied needle was passed through the apex of the heart to attach the apex to a light weight, rigid coupling rod, which in turn was attached to a force transducer (Statham, Gould Inc., Cleveland, $\mathrm{OH}$ ). The tension of the suture was adjusted to generate a resting (diastolic) force of $\sim 1 \mathrm{~g}$.

The temperature of the heart (sensed in the right ventricle) was maintained at $37 \pm 0.2^{\circ} \mathrm{C}$ by warming the perfusion fluid by means of warm water circulating (Lauda T1, Messgerate, Germany) in the jacketing of a bubble trap and heat exchanger. During ischemia, the temperature of the heart was maintained by lowering the heart and the lower portion of the coupling rod into an organ bath containing modified Tyrode's solution at $37^{\circ} \mathrm{C}$. The frequency response of the force transducer, coupling rod, and mounting gantry was flat to at least $50 \mathrm{~Hz}$.

At appropriate time points during the experiment, the force developed by the heart was recorded at fast paper speed $(100 \mathrm{~mm} / \mathrm{s}$, Gould Mark 200 recorder; Gould Inc.), and coronary effluent was collected over $30 \mathrm{~s}$. These timed collections were weighed to measure coronary flow and then frozen for the subsequent analysis of creatine kinase (CK) activity.

The Langendorff perfusion protocol. The operator was unaware of the transgene status of the mice at the time of Langendorff perfusion.

After commencing retrograde aortic perfusion at a pressure of $\mathbf{8 0}$ $\mathrm{mmHg}$, hearts were allowed to stabilize, and after $\sim 20 \mathrm{~min}$ baseline contractility and coronary flow measurements were made. Hearts were then lowered into the organ bath, and coronary flow was stopped for a period of $20 \mathrm{~min}$. After this period, flow was recommenced at $80 \mathrm{mmHg}$. At predetermined time points, collections of coronary effluent and records of heart contraction at fast paper speed were made to generate profiles during reperfusion, contractile recovery, heart rate, coronary flow, and CK efflux. At the end of the reperfusion period, the zone of myocardial infarction within each heart was measured as described below.

The assessment of the amount of infarction. At the end of the experimental procedure, the heart was again lowered into the organ bath, and a $10 \%$ (wt/vol) solution of triphenyltetrazolium in phosphate buffer $\left(\mathrm{Na}_{2} \mathrm{HPO}_{4} 88 \mathrm{mM}, \mathrm{NaH}_{2} \mathrm{PO}_{4} 1.8 \mathrm{mM}\right)$ was infused into the coronary vasculature through the sidearm of the aortic cannula. Once the heart had become discolored (tetrazolium stains the viable myocardium deep red) it was removed from the aortic cannula, blotted dry, weighed, and frozen at $-70^{\circ} \mathrm{C}$.

At a later date the hearts, while still frozen, were sliced into sections $\sim 0.8 \mathrm{~mm}$ thick in a plane perpendicular to their long axis and approximately parallel to the atrioventricular groove. Sections were then fixed in $2 \%$ paraformaldehyde overnight. The following day, slices were orientated caudal surface upward and compressed, together with a calibration grid, between two Plexiglas plates separated by $0.57-\mathrm{mm}$ spacers. Heart slices were then illuminated, and a magnified video image was digitized (QuickCapture Frame Grabber Board; Data Translation Inc., Marlboro, MA and NIH Image v1.5; National Institutes of Health, Bethesda, MD). For each slice, the area of infarction and the total area of the slice were planimetered (see Discussion), and area was expressed in arbitrary units, calculated by Simpson's rule. These units were then converted to square millimeters by normalizing to the area of the calibration grid at the same magnification. Slices that contained atrial or valvular tissue were excluded from the analysis. The areas of infarction and the overall areas of the individual slices from each heart were then summed. In this manner a total area of infarction and a total area at risk of infarction were derived for each heart. These values were then multiplied by slice thickness $(0.57 \mathrm{~mm})$ to generate volume of infarction and volume at risk of infarction for each heart.

The measurement of CK efflux. The CK concentration in timed aliquots of the coronary effluent was measured spectrophotometrically using a commercial kit (catalogue No. 45-UV; Sigma Immunochemicals, St. Louis, MO). CK was then expressed as activity leaked per min per gram wet weight of heart.

The measurement of myocardial catalase. Catalase is a ubiquitous tissue enzyme that catalyzes the conversion of $\mathrm{H}_{2} \mathrm{O}_{2}$ to $\mathrm{H}_{2} \mathrm{O}$ and $\mathrm{O}_{2}$. In the heart, it may be capable of attenuating free-radical injury by preventing the conversion of $\mathrm{H}_{2} \mathrm{O}_{2}$ to more reactive species (14).

Transgene positive and transgene negative mice were anesthetized, hearts were removed, and aortas were cannulated and retrogradely perfused with Tyrode's solution as described above. Once the blood had been washed out of the coronary circulation and the left and right ventricular cavities, hearts were removed from the perfusion rig, weighed, and homogenized for the analysis of catalase using a modification of a previously described method (25).

In brief, $100 \mathrm{mg}$ of heart tissue was Dounce homogenized in $1 \mathrm{ml}$ of isotonic sodium phosphate buffer with $1 \%$ ethanol. After centrifugation and the addition of $1 \%$ Triton X-100, supernatants were diluted 10 fold in phosphate buffer with $1 \%$ ethanol. Two $0.25-\mathrm{ml}$ aliquots were then taken. To one aliquot (test), $2.5 \mathrm{ml}$ of $6 \mathrm{mM} \mathrm{H}_{2} \mathrm{O}_{2}$ in potassium phosphate buffer was added, and the decomposition of $\mathrm{H}_{2} \mathrm{O}_{2}$ was allowed to proceed for exactly $3 \mathrm{~min}$ after which the reaction was terminated by the addition of $0.5 \mathrm{ml}$ of $6 \mathrm{~N} \mathrm{H}_{2} \mathrm{SO}_{4}$. To the other aliquot (blank), $\mathrm{H}_{2} \mathrm{SO}_{4}$ was added before $\mathrm{H}_{2} \mathrm{O}_{2}$. All the above reactions were performed at $4^{\circ} \mathrm{C}$. The remaining $\mathrm{H}_{2} \mathrm{O}_{2}$ in both test and blank was then quenched by the addition of $3.5 \mathrm{ml}$ of $0.01 \mathrm{M} \mathrm{KMnO}_{4}$, and absorption at $480 \mathrm{~nm}$ was recorded to derive $\mathrm{Abs}_{\text {test }}$ and $\mathrm{Abs}_{\text {blank }}$, respectively. The absorbance at $480 \mathrm{~nm}$ of $3.5 \mathrm{ml}$ of $0.01 \mathrm{KMnO}_{4}$ in $2.75 \mathrm{ml}$ of potassium phosphate buffer with $0.5 \mathrm{ml} 6 \mathrm{~N} \mathrm{H}_{2} \mathrm{SO}_{4}$ was also recorded to derive $\mathrm{Abs}_{\text {std }}$. Catalase activity in the heart was then defined as $\log \left[\left(\mathrm{Abs}_{\text {std }}\right.\right.$ $\left.\left.-\mathrm{Abs}_{\text {blank }}\right) \div\left(\mathrm{Abs}_{\text {std }}-\mathrm{Abs}_{\text {test }}\right)\right] \times(400 \times 2.3 \div 180) \mathrm{U} / \mathrm{g}$ wet weight.

Statistical analysis. Results are expressed as means with standard errors determined by conventional methods. Statistical comparisons were performed between transgene positive and negative hearts at individual time points by using the Student's two-tailed, unpaired $t$ test. The effect of the transgene was examined between baseline and the 30min time point by two-way analysis of variance. All analyses were performed using the Statview v4.0 statistical package (Abacus Concepts Inc., Berkeley, CA). A probability value $\leq \mathbf{0 . 0 5}$ was considered significant, and a value $0.1 \leq P \leq 0.05$ was marginally significant.

\section{Results}

Experimental exclusions and group sizes. In one transgene positive and one transgene negative heart, coronary flows were very high and on close inspection tears were evident in the aortic root below the level of the coronary tie necessitating exclusion. One transgene negative experiment was also excluded because of intractable arrhythmias during the stabilization period. All of these exclusions occurred at the time of experimentation and no data were gathered. One unblinded transgene negative experiment was therefore performed to ensure equal group size. Each group consisted of 15 experiments.

Two durations of reperfusion were used. In the first set of experiments ( $n=7$ for each group) reperfusion was for 30 min. However, because of a theoretical possibility that this short reflow period would not be of adequate duration for the washout of the enzymatic cofactor giving rise to the tetrazolium stain (26), more experiments ( $n=8$ for each group) were performed with a 120-min period of reperfusion. Therefore the data comprise of information from 15 hearts in each group, apart from the $60-, 90-$, and 120-min reperfusion time points where data are derived from 8 hearts in each group. 
The size of the infarction zone was similar within hearts from the same group, whether reperfused for 30 or $120 \mathrm{~min}$, therefore all available hearts were used in the final analysis.

In three transgene negative hearts, infarct size could not be determined. In one experiment, the heart came off the aortic cannula during tetrazolium infusion and could not be resuspended. In two other (consecutive) experiments, there was no tetrazolium staining implying either complete infarction or failure of staining. Since these hearts had some contractile function, a fault in the staining technique was assumed.

A further 18 mice were used for characterization studies. Five transgene negative and three transgene positive hearts were used to measure catalase. The hearts of a further 10 mice were used for the preparation of protein and RNA.

Characterization of hearts from transgenic mice. The hearts from transgene positive and transgene negative mice (designated on the basis of Southern analysis of genomic DNA obtained from tail clips) were analyzed by Northern and Western blotting.

Western blots were probed with a polyclonal antibody (27) that recognizes both constitutive and inducible forms of hsp70 and with a monoclonal antibody (C92F3A-5; StressGen Biotechnologies Corp., Victoria, British Columbia) that only recognizes the inducible form of hsp70. As can be seen in Fig. 2, the hearts from transgene positive mice have appreciable hsp70i immunoreactivity, and the amount of constitutive hsp70 (hsp70c) protein (Fig. $2 \mathrm{~A}$ ) does not appear to be significantly altered by the expression of the transgene. At approximately equal protein loading, the myocardial hsp70i immunoreactivity in transgene positive mice is much greater than that seen after heat stress. In contrast to our findings in larger rodents $(2,6$, 10 ), whole body heat stress in the mouse appears to be a relatively poor stimulus for the induction of hsp70 within the heart compared with other organs. This finding is in keeping with previous reports (24). A possible explanation for this low level of induction is that the blood returning to the left heart has been cooled by room air during passage through the lungs and is therefore able to reduce myocardial temperature. In addition, the larger surface area/body weight ration in the mouse compared with larger rodents results in more rapid equilibration of core to environmental temperature. Thus, for a heat shock procedure where core temperature is elevated to $42^{\circ} \mathrm{C}$ for 15 min, the duration of time that core temperature is greater than basal temperature is much shorter for the mouse than for larger species.

Fig. 3 shows the Northern blot of cardiac $(A)$ and skeletal muscle $(B)$ RNA from a transgene positive mouse, a transgene negative mouse, and a transgene negative mouse $8 \mathrm{~h}$ after whole body heat stress. After heat stress the endogenous mouse hsp70i mRNAs are barely perceptible in cardiac tissue, but the previously described A and B forms (21) are clearly seen in skeletal muscle. The disparate levels of mRNA induction in heart and skeletal muscle are in keeping with the weak induction of myocardial hsp70i protein described above (Fig. 2). The chimeric transgene (containing the rhsp70i B form) is transcribed into an mRNA of a unique size due to the addition of chimeric hybrid sequences derived from the chicken $\beta$-actin gene before the translation start site and from SV40 after the translational stop site. The resultant chimeric transcript has a size of $2.6 \mathrm{~kb}$ and migrates between the mRNAs for the two endogenous mouse hsp70i transcripts with sizes of 2.7 and $2.5 \mathrm{~kb}$. In sum-

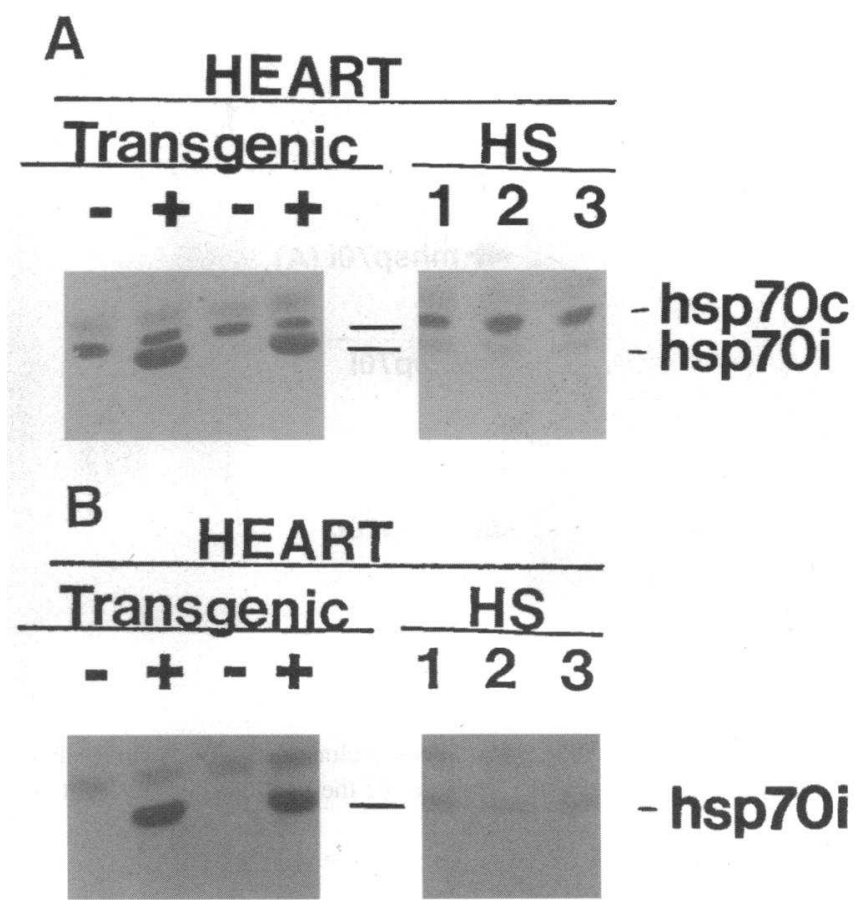

Figure 2. Western blot of samples prepared from hearts harvested from transgene positive and transgene negative mice after whole body heat stress. The samples are probed with a polyclonal $(A)$ and a monoclonal $(B)$ antibody recognizing hsp70. In both panels, (lanes from left to right ) - denotes transgene negative; + denotes transgene positive; and 1,2 , and 3 are samples from transgene negative mice harvested 8-24 $\mathrm{h}$ after heat shock. $(A)$ The primary polyclonal antibody recognizes constitutive (hsp70c) and inducible (hsp70i) forms of the 70-kD heat shock protein. hsp70c runs above hsp70i. A strong hsp70i signal is seen in the hearts of transgene positive mice and no signal is seen in transgene negative littermates. The signal is present, but weak, in hearts harvested from transgene negative mice after heat stress $(H S)$. For a discussion of the reasons for the weak hsp70i signal after heat stress, see text. (B) The primary monoclonal antibody recognizes only the hsp70i band, the upper band is a nonspecific signal. The immunoreactive staining confirms that the pattern seen with the polyclonal antibody is indeed due to hsp70i rather than a degradation product of hsp70c.

mary, the novel chimeric rhsp70i RNA is the transcript responsible for the excess hsp70i immunoreactivity seen in Fig. 2 .

In the heart (Fig. $3 A$ ) the level of mRNA for hsp70c is not altered by overexpression of rhsp70i protein or by the presence of abundant transgenic mRNA.

Analysis of RNA from transgene negative and transgene positive hearts showed no differences in the level of expression of the hsp27, hsp60, and hsp90 heat shock protein genes (data not shown).

The catalase activity within the myocardium was unaltered by the presence and expression of the transgene. The activity in transgene positive myocardium was $1.45 \pm 0.47 \mathrm{U} / \mathrm{g}$ wet wt $(n=3)$ and in transgene negative myocardium was $1.53 \pm 0.38$ $\mathrm{U} / \mathrm{g}$ wet wt $(n=5)$.

Baseline characteristics of the Langendorff hearts. Despite high levels of rhsp70i expression in skeletal muscle, brain, and heart, transgene positive mice appeared normal. The average body weight, heart weight, and heart performance were similar in littermates with an without the transgene (see Table I). Since basal characteristics were similar between groups, contractile 
A

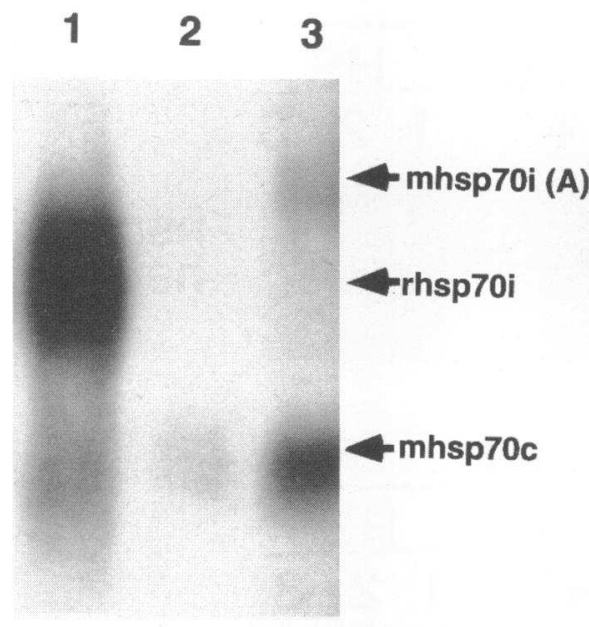

B

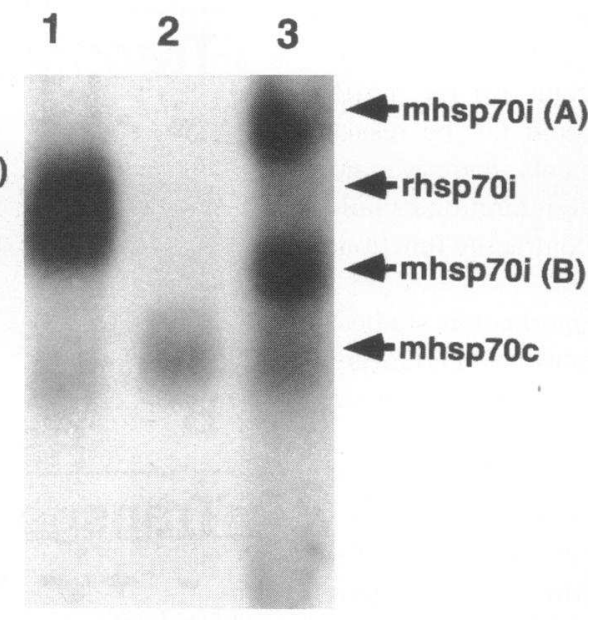

Figure 3. RNA analysis of hearts $(A)$ and skeletal muscles $(B)$ harvested from a transgene positive mouse, a transgene negative mouse, and a transgene negative mouse $8 \mathrm{~h}$ after whole body heat stress. In both $A$ (heart) and $B$ (skeletal muscle), lane $l$ is prepared from a transgene positive mouse, lane 2 a transgene negative mouse, and lane 3 a transgene negative mouse $8 \mathrm{~h}$ after heat stress. $A$ shows that the transcript for the rat inducible $70-\mathrm{kD}$ heat shock protein (rhsp70i), seen only in transgene positive hearts, runs above that for the mouse constitutive heat shock protein $70(\mathrm{mhsp} 70 \mathrm{c})$ and below that for the mouse inducible heat shock protein 70 ( mhsp70i). The unique size of the rhsp70i transgene transcript is due in part to the additional sequences before the transcriptional start and after the transcriptional stop codons ( see Fig. 1). $B$ is prepared from skeletal muscle where the heat shock

response is more marked and has been included to show the signals of both forms (A and B) of mhsp70i. The size of the chimeric transgene remains unique. The possible reasons for the poor signal after heat stress in cardiac compared with skeletal muscle are discussed in the text. data for each individual experiment were expressed as a percentage of the baseline value.

Developed force at baseline tended to be higher in transgene positive hearts, however these hearts also tended to be slightly larger so that myocardial tension, if measured, would have been similar.

The performance of the Langendorff heart. Initial experiments were performed on the hearts from transgene negative mice with 30 and then 25 min of no-flow ischemia. Contractile recovery in these experiments was below $5 \%$, so the ischemic time was shortened to $20 \mathrm{~min}$. This duration of ischemia is classically thought to result in only minimal irreversible cardiac injury or necrosis (28). However, in view of the very poor contractile recovery, we felt that the mouse heart was unusually susceptible to infarction, possibly because of high intrinsic heart rates and therefore metabolic rates.

Contractility in the isolated heart was measured as the difference between the systolic and diastolic force generated at the apical force transducer as the heart attempted to shorten between the apical force transducer and aortic cannula. As shown in Fig.

Table I. Baseline Characteristics of Transgene Positive and Transgene Negative Mice

\begin{tabular}{lcc}
\hline \multirow{2}{*}{\multicolumn{1}{c}{ Characteristic }} & \multicolumn{2}{c}{ Transgene status } \\
\cline { 2 - 3 } & + & - \\
\hline Body wt $(\mathrm{g})$ & $26.7 \pm 1.2$ & $25.9 \pm 1.1$ \\
Heart wt (mg)* & $147.4 \pm 7.3$ & $135.3 \pm 9.0$ \\
Baseline flow (ml/min) & $3.82 \pm 0.22$ & $3.77 \pm 0.17$ \\
Baseline developed force $(g)$ & $2.72 \pm 0.29$ & $2.61 \pm 0.37$ \\
Baseline diastolic force $(g)$ & $1.06 \pm 0.09$ & $1.14 \pm 0.10$ \\
& & \\
\end{tabular}

* Heart wet weight was measured at the end of the experimental protocol after $20 \mathrm{~min}$ of global ischemia and up to $120 \mathrm{~min}$ of reperfusion. Developed force was peak systolic force minus diastolic force. Diastolic force was measured at end diastole. $n=15$ for each group.
4 , although contractility in both groups was severely reduced after $20 \mathrm{~min}$ of zero-flow ischemia, hearts from transgene positive mice had better postischemic recovery. Most hearts showed a paradoxical hypercontractile phase during the first 2 min of

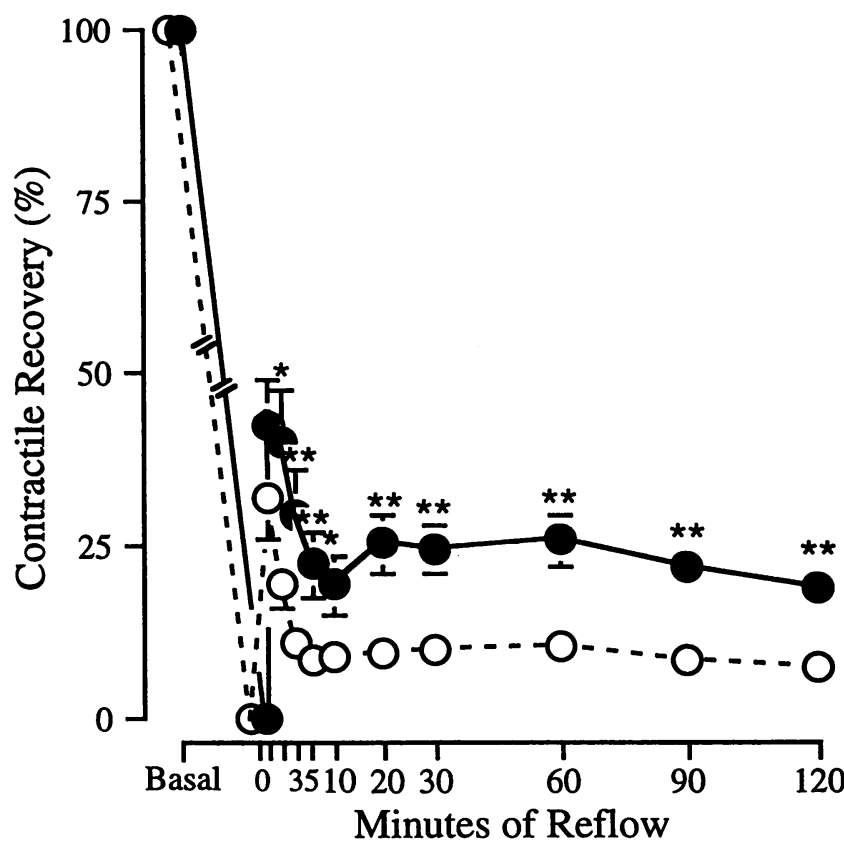

Figure 4. Contractile recovery of the isolated mouse heart after $20 \mathrm{~min}$ of global ischemia. Force between an apical force transducer and the aortic cannula was measured during each contraction. Contractility was defined as developed force calculated by subtracting diastolic force from peak systolic force. At each time point, contractility during reflow was expressed as a percentage of basal contractility. $O$, transgene negative hearts; •, transgene positive hearts. Bars represent one standard error of mean, $* P \leq 0.05, * * P \leq 0.01$, two-way analysis of variance, $P$ $=0.01$ for the effect of group. Basal to 30 min reflow, $n=15$ for each group; 60-90 $\mathrm{min}$ of reflow, $n=8$ for each group. 


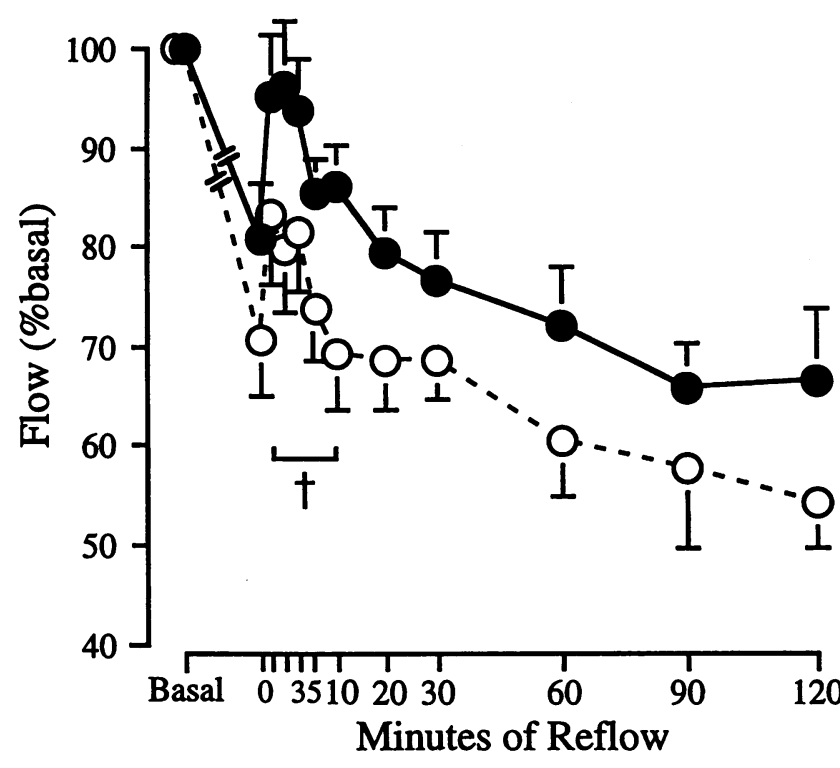

Figure 5. Changes in coronary flow after $20 \mathrm{~min}$ of global ischemia. Coronary flow was measured by collecting and weighing the coronary effluent. Flow at each time point was expressed as a percentage of baseline flow. $O$, transgene negative hearts; $\bullet$, transgene positive hearts. Bars represent one standard error of mean. There was no significant difference between groups at each time point, two way analysis of variance $P=0.046$ for the effect of group. Between 2 and $10 \mathrm{~min}$ of reflow the differences between the groups were marginally significant, ${ }^{\dagger} 0.08>P>0.05$. Basal to $30 \mathrm{~min}$ reflow, $n=15$ for each group; $60-$ $90 \mathrm{~min}$ of reflow, $n=8$ for each group.

reperfusion which subsequently decayed, so that developed force was fairly constant between 5 and $120 \mathrm{~min}$ of reperfusion (see Fig. 4). Postischemic developed force in transgene positive hearts was approximately twice that of hearts from transgene negative littermates (at the 30 -min time point, transgene positive $24.3 \pm 3.7 \%, n=15$ compared with transgene negative 9.6 $\pm 2.1 \%, n=15, P=0.002$ ).

The better contractile recovery was associated with higher postischemic coronary flows in the hearts from transgene positive mice (see Fig. 5). Since coronary perfusion pressure was constant, coronary flow reflects coronary vascular resistance. It is likely that the lower coronary flow in transgene negative hearts is secondary to no reflow within the larger areas of infarction seen in these hearts (see below). In addition diastolic force and therefore tension tended to be higher in these hearts (data not shown), and this would also have acted to impede flow. The cause for the gradual reduction in coronary flow seen in both groups during the course of reperfusion is not known, but this phenomenon is often seen in the postischemic Langendorff heart (29).

The heart rates between experimental groups were similar, though variable in individual preparations (Fig. 6). Hearts were not paced, but rates did not differ significantly at baseline or during the first $180 \mathrm{~s}$ of ischemia. Beyond $180 \mathrm{~s}$ contractile amplitude was insufficient to measure rate. Small differences in baseline heart rate between groups are unlikely to account for large differences in postischemic contractile recovery. In our experiments basal heart rate did not correlate with either contractile recovery at $\mathbf{3 0} \mathrm{min}$ or normalized infarct size (data not shown). It is therefore unlikely that a fast heart rate before

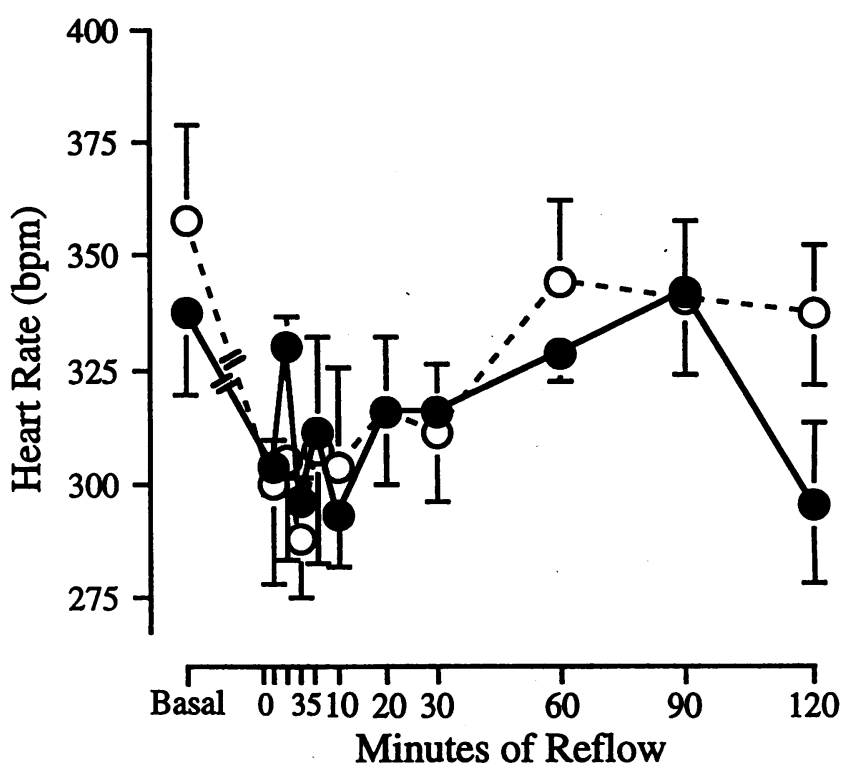

Figure 6. Heart rate before and during reflow after $20 \mathrm{~min}$ of global ischemia. Hearts were not paced. The slight difference in heart rates at baseline did not alter postischemic performance (see Results). $০$, transgene negative hearts; $\bullet$, transgene positive hearts. Bars represent one standard error of mean. There was no significant difference between groups at each time point, two way analysis of variance $P=0.91$ for the effect of group. Basal to $30 \mathrm{~min}$ reflow, $n=15$ for each group; 60-90 $\min$ of reflow, $n=8$ for each group.

ischemia increased the metabolic demands of the myocardium and sensitized the heart to ischemic injury (28). Moreover, when the transgene positive experiments with the three slowest initial heart rates were excluded, mean basal heart rates for transgene positive and transgene negative groups became identical ( 355 and $357 \mathrm{bpm}$, respectively), but contractility at 30 $\min (21.7 \pm 3.4 \% n=12$ and $9.6 \pm 2.1 \% n=15, P \leq 0.01$, respectively) and normalized infarct size $(27.6 \pm 2.7 \% n=12$ and $45.1 \pm 3.6 \% n=12, P \leq 0.01$, respectively) continued to indicate a significant reduction in the extent of ischemic injury in transgene positive hearts.

The efflux of $C K$. The efflux of CK during reperfusion is shown in Fig. 7. CK efflux was significantly reduced in transgene positive hearts reflecting the greater contractile recovery seen in this group. The CK activities at each time point had considerable variability, hence standard errors are large and individual time points fail to reach statistical significance.

Myocardial infarct size. Tetrazolium stains viable myocardium deep red. Figs. 8 and 9 show the staining pattern of slices from a transgene positive and transgene negative heart, respectively. In this example there is a small discrete, predominantly subendocardial area of infarction in the transgene positive heart. The area of infarction in the transgene negative heart is less contiguous and much more extensive. Like the heart in Fig. 8, a number of hearts showed epicardial necrosis that was geographically separate from the larger area of endocardial necrosis (see Discussion). When the slices from all the hearts were analyzed, the total volume of myocardial infarction was significantly greater in the transgene negative hearts. Moreover, these differences in infarct size became even more significant when volumes of infarction for each heart were normalized by total volume at risk of infarction (see Fig. 10). 


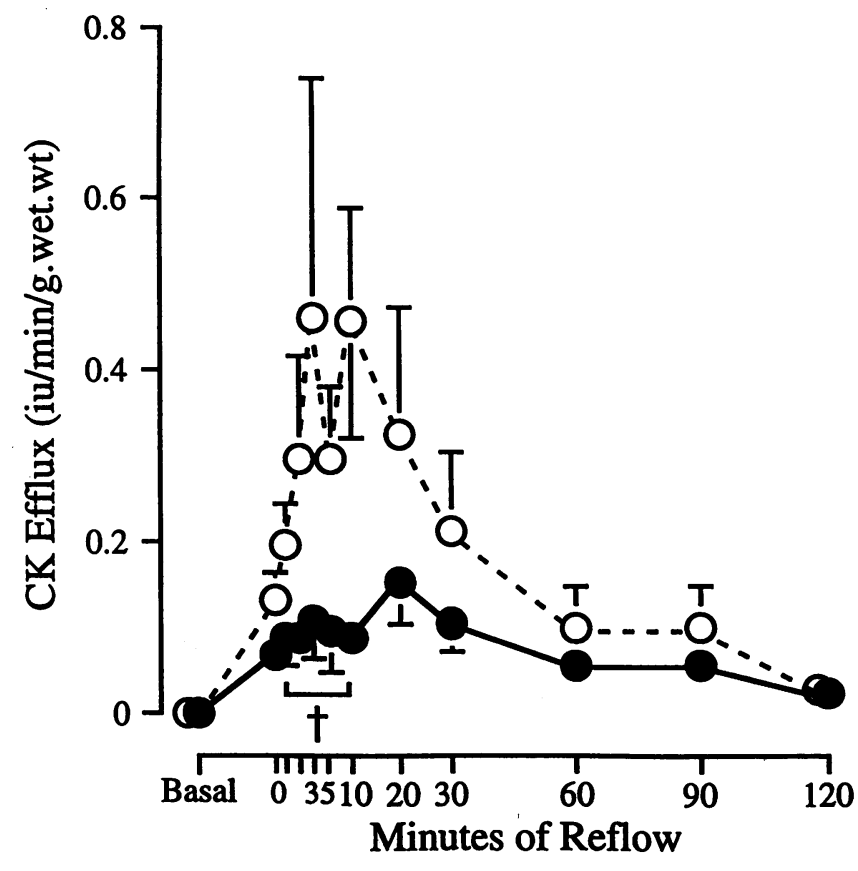

Figure 7. CK efflux during reflow after $20 \mathrm{~min}$ of global ischemia. There was no detectable CK activity in the coronary effluent at baseline. During reflow, the CK contents of the coronary effluents varied widely, but at each time point activity was less in transgene positive hearts. $O$, transgene negative hearts; $\bullet$, transgene positive hearts. Bars represent one standard error of mean. There was no significant difference between groups at each time point, two way analysis of variance $P=0.04$ for the effect of group. Between 1 and 10 min of reflow the differences between the groups were marginally significant ${ }^{\dagger} 0.09>P>0.05$. Basal to $30 \mathrm{~min}$ reflow, $n=15$ for each group; 60-90 $\mathrm{min}$ of reflow, $n=8$ for each group.

After ischemia the percentage of contractile recovery (see Fig. 4) was less than the percentage of viable myocardium (see Fig. 10). The implication was that in both groups some portion of the heart, though viable, was not contributing to contraction. Since perfusion had been restored, the most likely explanation for this discrepancy was that there was some degree of contractile stunning (30). Nonetheless, in individual hearts, normalized infarct size correlated significantly with contractile performance (see Fig. 11). This observation suggests that infarction also contributed significantly to the contractile deficit.

\section{Discussion}

Previous studies have shown that myocardial protection follows whole body heat stress. The cause for this protection is uncertain, although increases in myocardial hsp70i and possibly myocardial catalase have been considered $(8,9)$. In this study we have shown that myocardial protection occurs in transgenic mice overexpressing hsp70i in their hearts, without alteration in myocardial catalase. This observation strongly supports the hypothesis that hsp70i is a cytoprotective protein within the heart and is at least partially responsible for the myocardial protection that follows whole body heat stress. Our findings are in keeping with previous observations that overexpression of hsp70 confers protection against simulated ischemia and thermal stress in isolated heart or muscle-derived cells $(12,13$, 31,32 ).
The mechanisms by which hsp70 may result in myocardial protection. hsp70i is a member of the family of proteins known as chaperones (33). These proteins function in a variety of well described circumstances to promote correct protein folding and prevent inappropriate protein interactions $(34,35)$. The mechanisms whereby such functions can protect the myocardium from ischemic damage are necessarily speculative since the precise cause for cell death during ischemia is unknown.

During ischemia the cellular internal milieu changes profoundly with the intracellular accumulation of protons and sodium ions (36). These changes are compounded by the freeradical stress and the marked increase in intracellular calcium associated with reperfusion (37). Under these circumstances, the tertiary structure of proteins may change sufficiently to alter function. Such ischemia-induced changes in protein conformation and function have been described for the key metabolic enzyme carnitine palmitoyltransferase (38). In our experiments, the presence of an excess of hsp70 may prevent these adverse conformational changes or promote the correct refolding of denatured proteins once the cell reenergizes during reperfusion. Further evidence in support of this hypothesis is the fact that myocardial ischemia is a potent stimulus for the induction of hsp70i $(2,17,39)$. This suggests that some component(s) of the ischemic injury is able to activate hsp70 gene expression, a process known to be triggered by the presence of denatured proteins $(40,41)$ and ATP depletion $(32,41)$. The intronless gene arrangement and the preferential translation of hsp70 in such circumstances intimate its special role in the ischemic/ reperfused heart (42). It is therefore possible that an overabundance of hsp70 before ischemia, as occurs in the transgenic heart, is able to attenuate the consequences. of ischemia at the protein level. A similar explanation is thought to underlay the resistance to thermal injury that accompanies overexpression of hsp70 $(31,43)$ and the sensitization to thermal injury that accompanies diminished expression of hsp70 (44). Thus, thermal and ischemic injuries may be prevented by overexpression of hsp70 because they have protein denaturation as a common pathology.

During ischemia, ATP levels fall, preventing protein translation (45). In this circumstance, nascent polypeptides, representing incompletely translated mRNA, are exposed to the ionic perturbations described above. Under normal conditions, during the course of translation, these immature proteins associate with a series of chaperones and chaperonins including hsp70 (46). These associations are thought necessary to suppress and reverse polypeptide chain interactions that would otherwise result in a nonfunctional, incorrectly folded protein $(46,47)$. Consequently, chaperones may also play a role in the recovery of translation with the restoration of useful protein synthesis on reperfusion. The availability of these newly synthesized proteins may be crucial to the recovery of the ischemically injured cell.

Implications and future directions. Our findings show that it is probably possible to overexpress hsp70i within the heart without any apparent detrimental effect. This finding is surprising since in cell culture overexpression of the human inducible hsp70 gene slows cell growth (12). However, this gene is able to confer protection independent of its effect on cell growth (12). In addition, it is thought that hsp70 regulates its own transcription by interacting with the heat shock transcription factor to prevent binding to the heat shock element (48). One might expect, therefore, that overexpression of the rhsp70i may reduce the expression of the endogenous mouse hsp70s. How- 


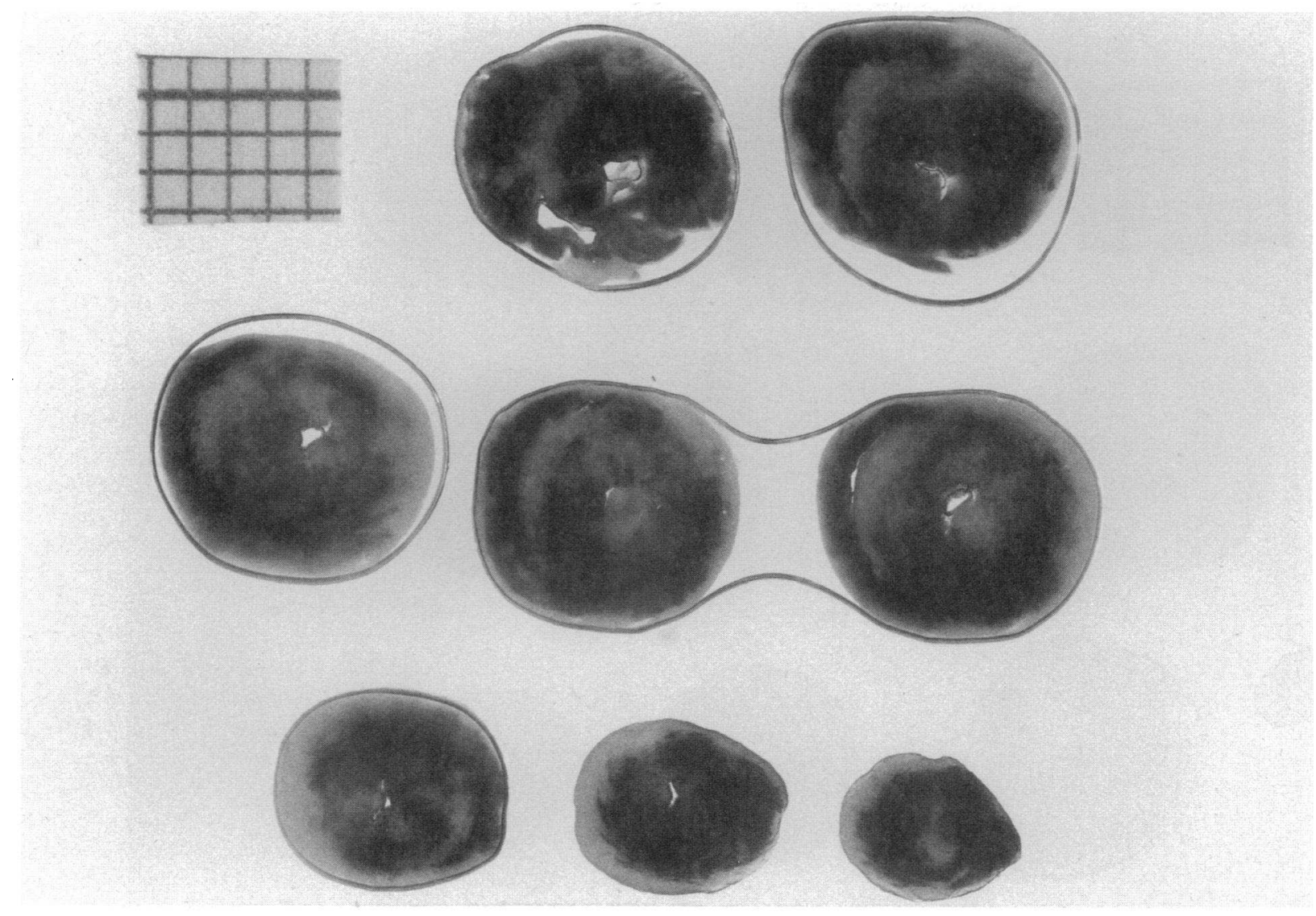

Figure 8. Myocardial infarction caused by $20 \mathrm{~min}$ of global ischemia delineated by tetrazolium staining in a heart from a transgene positive mouse. The heart has been sliced transversely from base to apex. Tetrazolium fails to stain nonviable myocardium, which remains pale. The pale area of necrosis is predominantly subendocardial with a separate, almost circumferential, area of epicardial necrosis closer to the apex of the heart. The calibration squares are $1 \mathrm{~mm}$.

ever, no reduction was seen in the mouse hsp70c mRNA of protein. This finding reflects our previous observation in a myogenic cell line where overexpression of human hsp70i did not alter the expression of the rat hsp70c (12). We conclude, therefore, that it is possible to overexpress hsp70i without disturbing the expression of the endogenous constitutive hsp70 genes. However, we have not excluded an effect of the transgene on expression of endogenous hsp70i and other hsp genes at the protein level.

In a previous study, constitutive overexpression of hsp70 in Drosophila cells led to the sequestration of hsp70 into granules, where it was inactivated and unable to confer thermoresistance (49). However, similar sequestration was not seen in rodent cells overexpressing hsp70 (50) which, consistent with our findings, had a protected phenotype.

Our ability to overexpress hsp70i within the heart and protect the myocardium without any apparent detrimental effects introduces the possibility of future therapeutic opportunities.

In the past decade, the treatment of acute myocardial infarction has been revolutionized by interventions which achieve early reperfusion, such as thrombolytic therapy and aspirin (51). Unfortunately, the mortality benefit of these interventions diminish if treatment is delayed (51). The finding that mortality can be reduced just by increasing the rate of infusion of a thrombolytic agent further underlines the importance of early reperfusion (52). Therefore, the ability of hsp70i to slow the progress of myocardial necrosis would act to increase the time window for effective reperfusion and thereby could further decrease mortality. Similar considerations are likely to apply in patients with unstable angina and in those undergoing cardiopulmonary bypass or high risk coronary angioplasty. In addition, the preservation of explanted hearts before transplantation may be improved. In all these situations the ability of hsp70i to delay the progression of ischemic myocardial damage could favorably influence the outcome.

If hsp70i was to be used as an adjunct to thrombolytic therapy, it would be necessary to increase the expression of this protein within the myocardium before infarction. Our results suggest that in patients at risk of myocardial infarction it may be possible to produce long-term overexpression of hsp70i without causing harm.

Study limitations. The use of tetrazolium to delineate regional infarction is a recognized technique (26). However, we are not aware that it has been used to demarcate infarction resulting from global ischemia in the mouse, although a similar technique has been used in other species $(53,54)$. In light of this, our results with respect to infarct size should be treated with caution.

A further difficulty we encountered with the assessment of infarction were areas of apical subepicardial loss of tetrazolium staining (see Fig. 8). These areas were probably related to the apical suture causing local myocardial distortion which impeded 


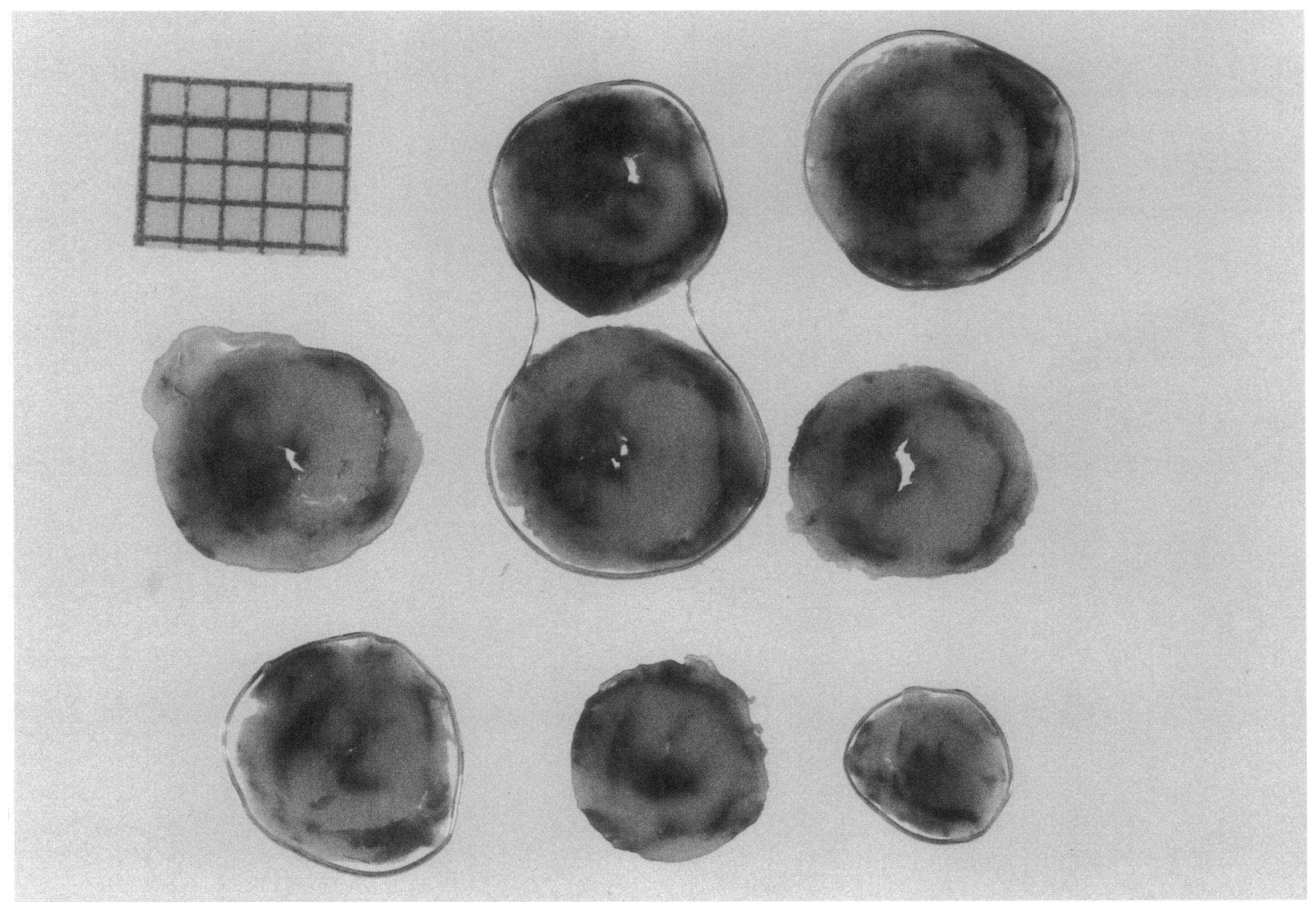

Figure 9. Myocardial infarction caused by $20 \mathrm{~min}$ of global ischemia delineated by tetrazolium staining in a heart from a transgene negative mouse. See legend to Fig. 8. Compared with the heart in Fig. 8, the area of necrosis is more extensive and less well circumscribed.

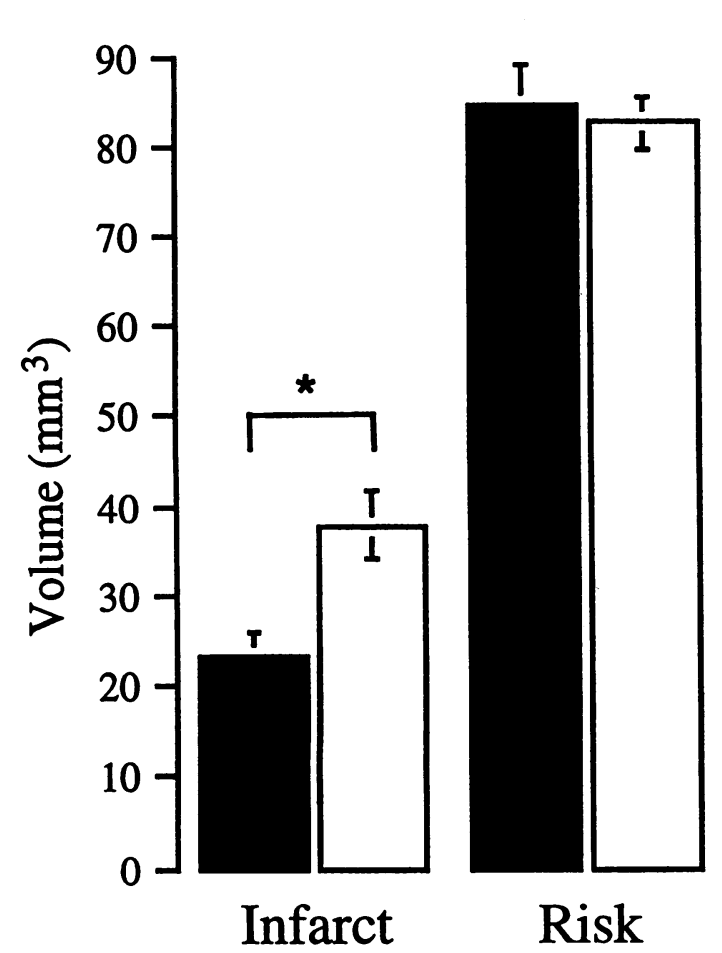

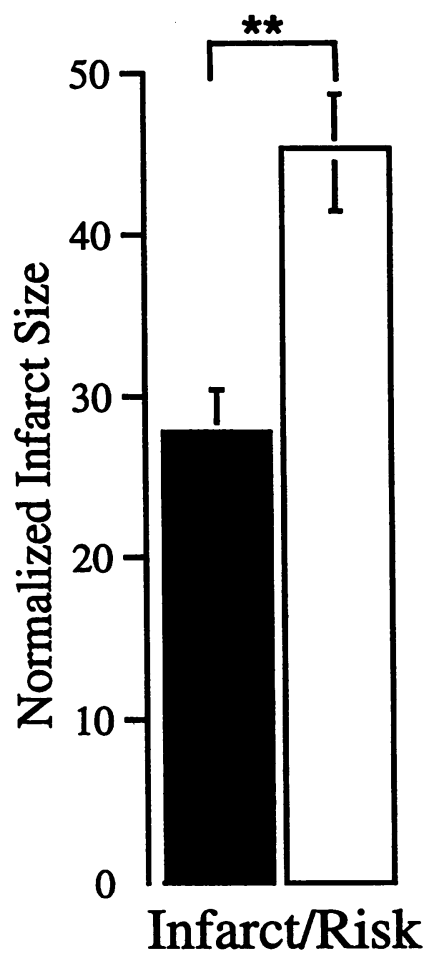

Figure 10. Myocardial, infarct, and risk volume and normalized infarct size after $20 \mathrm{~min}$ of global ischemia. Hearts were reperfused for 30 or $120 \mathrm{~min}$. $\square$, transgene negative, $n$ $=12 ; \mathrm{E}$, transgene positive, $n=15$. Bars represent one standard error of mean *P $\leq 0.05, * * P \leq 0.01$. 


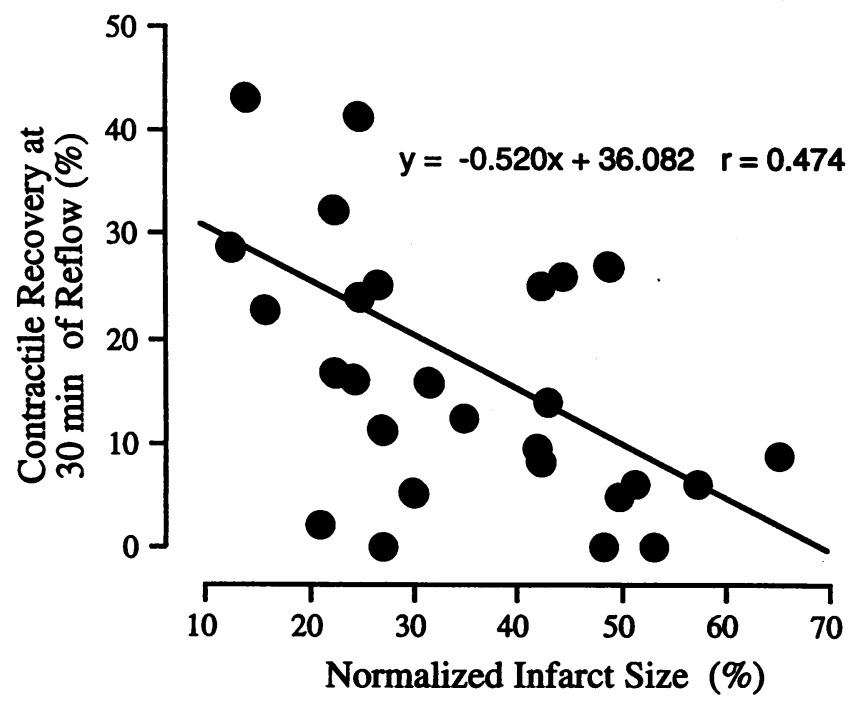

Figure 11. The relationship between normalized infarct size and contractile recovery at $30 \mathrm{~min}$ of reflow after $20 \mathrm{~min}$ of global ischemia. The data from transgene positive and negative experiments were both used for this analysis. There is a significant negative correlation between infarct size and contractile function $P=0.01$. The ordinate intercept is $36.1 \%$. This implies that even without infarction contractile recovery would have been incomplete and that therefore an element of contractile stunning is probably present (see Results).

capillary perfusion during early reperfusion when ischemic contracture was greatest. In a preliminary experiment performed without an apical suture, this artifact was absent. However, since the volumes of apical subepicardial infarction were small, they only had a significant effect on overall infarct size in those hearts with small volumes of subendocardial infarction. Thus, infarct size would be overestimated in those hearts with small infarcts and this would have mitigated against the separation we observed in infarct size between groups.

By using a chimeric promoter for the rhsp70i gene, we achieved high levels of transcription and translation within the myocardium. At a cellular level this high level of expression may have been at the expense of a lower level of expression of other genes which had to compete for the same transcriptional and translational machinery. It is therefore possible, but unlikely, that the protective benefits that we observed were not due to overexpression of hsp70i.

Conclusions. Hearts harvested from transgenic mice overexpressing myocardial hsp70i were resistant to ischemia. In these mice, postischemic contractile function was enhanced, intracellular enzyme efflux was reduced, and infarct size was diminished. In contrast to the changes occurring within the heart after whole body heat stress, an increase in myocardial catalase activity did not accompany the expression of the transgene. We conclude that hsp70i is able to protect the heart from ischemic injury and that it is probably responsible for the myocardial protection that follows whole body heat stress.

\section{Acknowledgments}

We thank J. Price (Scripps Clinic Research Foundation, La Jolla, CA) for producing the transgenic mouse line and Dr. C. Markert (North Carolina State University, Raleigh, NC) for providing us with the vector pCAGGS.
M. S. Marber is a British Heart Foundation Senior Lecturer. R. Mestril was supported by an American Heart Association Grant-inAid and National Institutes of Health grant K14-HL03150-01. W. H. Dillmann received support from the National Institutes of Health (grant HL-49343) and a US Army Acquisition and Development Award (DAMD17-93-5-3027).

\section{References}

1. Donnelly, T. J., R. E. Sievers, F. L. J. Vissern, W. J. Welch, and C. L. Wolfe. 1992. Heat shock protein induction in rat hearts. A role for improved myocardial salvage after ischemia and reperfusion? Circulation. 85:769-778.

2. Marber, M. S., D. S. Latchman, J. M. Walker, and D. M. Yellon. 1993 Cardiac stress protein elevation 24 hours after brief ischemia or heat stress is associated with resistance to myocardial infarction. Circulation. 88:1264-1274.

3. Currie, R. W., R. M. Tanguay, and J. G. Kingma. 1993. Heat-shock response and limitation of tissue necrosis during occlusion/reperfusion in rabbit hearts. Circulation. 87:963-971.

4. Walker, D. M., E. Pasini, S. Kucukoglu, M. S. Marber, E. Iliodromitis, R. Ferrari, and D. M. Yellon. 1993. Heat stress limits infarct size in the isolated perfused rabbit heart. Cardiovasc. Res. 27:962-967.

5. Currie, R. W., M. Karmazyn, M. Kloe, and K. Mailer. 1988. Heat shock response is associated with enhanced postischaemic ventricular recovery. Circ. Res. 63:543-549.

6. Yellon, D. M., E. Pasini, A. Cargnoni, M. S. Marber, D. S. Latchman, and R. Ferrari. 1992. The protective role of heat stress in the ischemic and reperfused rabbit myocardium. J. Mol. Cell. Cardiol. 24:342-346.

7. Amrani, M., N. J. Allen, J. O'Shea, J. Corbett, M. J. Dunn, S. Tadjkarimi, S. Theodoropoulos, J. Pepper, and M. H. Yacoub. 1993. Role of catalase and heat shock protein on recovery of cardiac endothelial and mechanical function after ischemia. Cardioscience. 4:193-198.

8. Yellon, D. M., D. S. Latchman, and M. S. Marber. 1993. Stress proteins, an endogenous route to myocardial protection: fact or fiction? Cardiovasc. Res. 27:158-161.

9. Black, S. C., and B. R. Lucchesi. 1993. Heat shock proteins and the ischemic heart. An endogenous protective mechanism. Circulation. 87:1048-1051.

10. Marber, M. S., J. M. Walker, D. S. Latchman, and D. M. Yellon. 1994 Myocardial protection following whole body heat stress in the rabbit is dependent on metabolic substrate and is related to the amount of the inducible 70-kD heat stress protein. J. Clin. Invest. 93:1087-1094.

11. Hutter, M. M., R. E. Sievers, V. Barbosa, and C. L. Wolfe. 1994. Heatshock protein induction in rat hearts. A direct correlation between the amount of heat-shock protein induced and the degree of myocardial protection. Circulation. 89:355-360.

12. Mestril, R., S.-H. Chi, M. R. Sayen, K. O'Reilly, and W. H. Dillmann. 1994. Expression of inducible stress protein 70 in rat heart myogenic cells confers protection against simulated ischemia-induced injury. J. Clin. Invest. 93:759767.

13. Heads, R. J., D. S. Latchman, and D. M. Yellon. 1994. Differences in the ability of transfected hsp70 and hsp90 genes to protect $\mathrm{H} 9 \mathrm{c} 2$ myocytes against heat stress and hypoxia. Circulation. 90(Suppl. I):I-537a. (Abstr.)

14. Yellon, D. M., and J. M. Downey. 1990. Current research views on myocardial reperfusion and reperfusion injury. Cardioscience. 1:89-98.

15. Karmazyn, M., K. Mailer, and R. W. Currie. 1990. Acquisition and decay of heat-shock-enhanced postischemic ventricular recovery. Am. J. Physiol. 259:H424-H431.

16. Steare, S. E., and D. M. Yellon. 1993. The protective effect of heat stress against reperfusion arrhythmias in the rat. J. Mol. Cell. Cardiol. 25:1471-1481.

17. Knowlton, A. A., P. Brecher, and C. S. Apstein. 1991. Rapid expression of heat shock protein in the rabbit after brief cardiac ischemia. J. Clin. Invest. 87:139-147.

18. Kuzuya, T., S. Hoshido, N. Yamashita, H. Fuiji, H. Oe, M. Hori, T. Kamada, and M. Tada. 1993. Delayed effects of sublethal ischemia on the acquisition of tolerance to ischemia. Circ. Res. 72:1293-1299.

19. Hoshida, S., T. Kuzuya, H. Fuiji, N. Yamashita, H. Oe, M. Hori, K. Suzuki, N. Taniguchi, and M. Tada. 1993. Sublethal ischemia alters myocardia antioxidant activity in canine heart. Am. J. Physiol. 264:H33-H39.

20. Welch, W. J. 1993. How cells respond to stress. Sci. Am. 268:34-41.

21. Mestril, R., S.-H. Chi, M. R. Sayen, and W. H. Dillmann. 1994. Isolation of a novel inducible rat heat shock protein (HSP70) gene and its expression during ischaemia/hypoxia and heat shock. Biochem. J. 298:561-569.

22. Niwa, H., K.-I. Yamamura, and J.-I. Miyazaki. 1991. Efficient selection for high-expression transfectants with a novel eukaryotic vector. Gene (Amst.). 108:193-200.

23. Hagan, B., F. Constanlini, and E. Lancy. 1986. Manipulating the mouse embryo. Cold Spring Harbor Press, Cold Spring Harbor, NY. 151-203.

24. Hotchkiss, R., I. Nunnally, S. Lindquist, J. Taulien, G. Perdrizet, and I. 
Karl. 1993. Hyperthermia protects mice against the lethal effects of endotoxin. Am. J. Physiol. 265:1447-1457.

25. Cohen, J., D. Dembiec, and J. Marcus. 1970. Measurement of myocardial catalase activity in tissue extracts. Anal. Biochem. 34:30-38.

26. Fishbein, M. C., S. Meerbaum, J. Rit, U. Lando, K. Kanmatsuse, J. C. Mercier, E. Corday, and W. Ganz. 1981. Early phase acute myocardial infarct size quantification: validation of the triphenyl terazolium chloride tissue enzyme staining technique. Am. Heart J. 101:593-600.

27. Mehta, H. B., B. K. Popovich, and W. H. Dillmann. 1988. Ischemia induces changes in the level of expression of mRNAs coding for stress protein 71 and creatine kinase. Circ. Res. 63:512-517.

28. Schaper, J., and W. Schaper. 1988. Time course of myocardial necrosis. Cardiovasc. Drugs Ther. 2:17-25.

29. Banerjee, A., C. Locke-Winter, K. B. Rogers, M. B. Mitchell, E. C. Brew, C. B. Cairns, D. D. Bensard, and A. H. Harken. 1993. Preconditioning against myocardial dysfunction after ischemia and reperfusion by an alpha ${ }_{1}$-adrenergic mechanism. Circ. Res. 73:656-670.

30. Bolli, R. 1990. Mechanism of myocardial stunning. Circulation. 82:723-

31. Heads, R. J., D. S. Latchman, and D. M. Yellon. 1994. Stable high level expression of transfected human hsp70 gene protects a heart-derived muscle cell line against thermal stress. J. Mol. Cell. Cardiol. 26:695-699.

32. Williams, R. S., J. A. Thomas, M. Fina, Z. German, and I. J. Benjamin. 1993. Human heat shock protein 70 (HSP 70) protects murine cells from injury during metabolic stress. J. Clin. Invest. 92:503-508.

33. Georgopoulos, C., and W. J. Welch. 1993. Role of the major heat shock proteins as molecular chaperones. Annu. Rev. Cell. Biol. 9:601-634.

34. Beckmann, R. P., L. A. Mizzen, and W. J. Welch. 1990. Interaction of HSP70 with newly synthesized proteins: implications for protein folding and assembly. Science (Wash. DC). 248:850-854.

35. Beckmann, R. P., M. Lovett, and W. J. Welch. 1992. Examining the function and regulation of hsp70 in cells subjected to metabolic stress. J. Cell Biol. 6:1137-1150.

36. Allen, D. G., and C. H. Orchard. 1987. Myocardial contractile function during ischemia and hypoxia. Circ. Res. 60:153-168.

37. Opie, L. H. 1989. Reperfusion injury and its pharmacological modification. Circulation. 80:1049-1062.

38. Pauly, D. F., K. A. Kirk, and J. B. McMillin. 1991. Carnitine palmitoyltransferase in cardiac ischaemia. A potential site for altered fatty acid metabolism. Circ. Res. 68:1085-1094.

39. Dillmann, W. H., H. B. Mehta, A. Barrieux, B. D. Guth, W. E. Neeley, and J. Ross. 1986. Ischemia of the dog heart induces the appearance of a cardiac mRNA coding for a protein with migration characteristics similar to heat-shock/ stress protein 71. Circ. Res. 59:110-114.
40. Ananthan, J., A. L. Goldberg, and R. Voellmy. 1986. Abnormal proteins serve as eukaryotic stress signals and trigger the activation of heat shock genes. Science (Wash. DC). 232:252-254.

41. Iwaki, K., S.-H. Chi, W. H. Dillmann, and R. Mestril. 1993. Induction of HSP70 in cultured rat neonatal cardiomyocytes by hypoxia and metabolic stress. Circulation. 87:2023-2032.

42. Yost, H. J., R. B. Petersen, and S. Lindquist. 1990. Posttranscriptional regulation of heat shock protein synthesis in Drosophila. In Stress Proteins in Biology and Medicine. R. I. Morimoto, A. Tissieres, and C. Georgopoulos, editors. Cold Spring Harbor Laboratory Press, Cold Spring Harbor, NY. 379-409.

43. Li, G. C., L. Li, Y. Liu, J. Y. Mak, L. Chen, and W. M. F. Lee. 1991. Thermal response of rat fibroblasts stably transfected with the human 70kDa heat shock protein+encoding gene. Proc. Natl. Acad. Sci. USA. 88:1681-1685.

44. Riabowol, K. T., L. A. Mizzen, and W. J. Welch. 1988. Heat shock is lethal to fibroblasts microinjected with antibodies against hsp70. Science (Wash DC). 242:433-436.

45. Williams, E. H., R. L. Kao, and H. E. Morgan. 1981. Protein degradation and synthesis during recovery from myocardial ischemia. Am. J. Physiol. 240:E268-E273

46. Frydman, J., E. Nimmesgern, K. Ohtsuka, and F. U. Hartl. 1994. Folding of nascent polypeptide chains in a high molecular mass assembly with molecula chaperones. Nature (Lond.). 370:111-117. 97.

47. Ellis, R. J. 1994. Chaperoning nascent proteins. Nature (Lond.). 370:96-

48. Baler, R., W. J. Welch, and R. Voellmy. 1992. Heat shock gene regulation by nascent polypeptides and denatured proteins: HSP70 as a potential autoregulatory factor. J. Cell Biol. 117:1151-1159.

49. Feder, J. H., J. M. Rossi, J. Solomon, and S. Lindquist. 1992. The consequences of expressing hsp70 in Drosophila cells at normal temperatures. Genes \& Dev. 6:1402-1413.

50. Rabindran, S. K., J. Wisniewski, L. Li, G. C. Li, and C. Lu. 1994 Interaction between heat shock factor and hsp70 is insufficient to suppress induction of DNA-binding activity in vivo. Mol. Cell. Biol. 14:6552-6560.

51. ISIS-2 (Second International Study of Infarct Survival) Collaborative Group. 1988. Randomized trial of IV streptokinase, oral aspirin, both, or neither among 17187 cases of suspected acute myocardial infarction. Lancet. ii:349-360.

52. The GUSTO investigators. 1993. An international randomized trial comparing four thrombolytic strategies for acute myocardial infarction. N. Engl. J. Med. 329:673-682.

53. Sandhu, R., R. J. Diaz, and G. J. Wilson. 1993. Comparison of ischaemic preconditioning in blood perfused and buffer perfused isolated heart models. Cardiovasc. Res. 27:602-607.

54. Jenkins, D. P., and D. M. Yellon. 1994. Ischaemic preconditioning in a surgically relevant model of global ischaemia. J. Mol. Cell. Cardiol. 26:LXX. (Abstr.) 